\title{
Tuning of Multivariable Decentralized PID Controller Using State Transition Algorithm
}

\author{
G. SARAVANAKUMAR ${ }^{1}$, K. VALARMATHI ${ }^{2}$, M. PALLIKONDA RAJASEKARAN ${ }^{1}$, Seshadhri \\ SRINIVASAN ${ }^{1}$, M. WILLJUICE IRUTHAYARAJAN ${ }^{3}$, Valentina E. BALAS ${ }^{4}$ \\ ${ }^{1}$ Department of Instrumentation and control Engineering, \\ Kalasalingam University, Krishnankoil, Tamilnadu, INDIA \\ saravana.control@gmail.com; mpraja83@gmail.com; seshucontrol@gmail.com \\ ${ }^{2}$ Department of Electronics and Communication Engineering, \\ PSR Engineering College, Sivakasi, INDIA \\ krvalarmathi@yahoo.co.in \\ ${ }^{3}$ Department of Electrical and Electronic Engineering, \\ National Engineering College, Kovilpatti, INDIA \\ m.willjuice@gmail.com \\ ${ }^{4}$ Department of Automation and Applied Informatics, \\ "Aurel Vlaicu" University of Arad, ROMANIA \\ balas@drbalas.ro
}

\begin{abstract}
Implementation of State Transition Algorithm (STA) for the tuning of multivariable Proportional Integral Derivative (PID) controller is reported. Two input and two output binary distillation column plant model by Wood and Berry is considered as a benchmark. Simulations are performed for three cases such as multivariable PID controller with decoupler, without decoupler and multivariable PI controller without decoupler. Integral of Time weighted Absolute Error (ITAE) and Integral of Absolute Error (IAE) are chosen as objective functions for the first case while Integral of Absolute Error alone is chosen for remaining couple of cases. Simulations are carried out for 20 independent trials by STA and STA with SBX crossover. Comparison of fitness value and time domain parameters for three cases against PBPSO is reported. Statistical performance measures of STA and STA-SBX algorithms are presented and simulation result implies that STA is a potential algorithm which provides better fitness for all the three cases and has global search capability. SBX crossover is enhanced by the consistency of the algorithm.
\end{abstract}

Keywords: Multivariable PID Controller Tuning, State Transition Algorithm, Distillation column, MIMO process.

\section{Introduction}

Proportional Integral Derivative controller is one of the simplest and most commonly used ones in various industries for control applications. Despite significant advancements in control technology, over $80 \%$ of industrial control loops are incorporated with PID controller. Though it is widely accepted, it should be properly tuned to meet desired behavior. Extensive work of Ziegler and Nichols [1] is the breakthrough in tuning methodology and Cohen Coon, Lambda tuning, and Chen Hrown Reswick (CHR) methods are a few of the other tuning methods reported in the literature [2]. Existing tuning methods are classified [3] based on nature and usage as analytical methods, Heuristic method, Frequency response method, Optimization method and Adaptive tuning methods. Among those, optimization method is widely utilized around the globe as it is conceptually simple and widely accepted one for tuning PID controller [2]. In this method, controller parameters are adjusted based on the chosen objective function chiefly integral performance measures. A classical optimization technique namely gradient method is often used to find optimal values. The shortcoming of gradient descent methods is sensitivity to the selection of initial values and their tendency to lock into a local extreme point [4]. Evolutionary Computation techniques are proposed to tune the PID controller by taking all non-linearity and additional process characteristics into account [5], [6]. Genetic Algorithm (GA) has the capability to solve nonlinear and complex optimization problems [7]. Porter and Jones proposed a GA-based simple and generic method of tuning digital PID controller [8].

Numerous work is available in the literature related to Distillation column control strategy [9-14]. Very recently, various optimization techniques such as Covariance Matrix Adaptation Evolution Strategy (CMAES), Particle Swarm Optimization (PSO), Differential Evolution (DE), Tribes Algorithm (TA), Ant Colony Optimization (ACO), Tabu 
Search Algorithm (TSA) and different Binary Particle Swarm Optimization are used to tune the PID control parameters [15-19]. Modified firefly algorithm for the tuning ofmultivariable PID controller is implemented for distillation column [20].

Iruthayarajan and Baskar compared the performance of various Real Coded Genetic Algorithm (RGA), Differential Evolution (DE), Modified Particle Swarm Optimization (MPSO) and Covariance Matrix Adaptation Evolution Strategy (CMAES) in the multivariable distillation column [21]. Discrete Binary PSO (DBPSO) algorithm, Probability based discrete binary PSO (PBPSO) and Modified Discrete Binary PSO (MDBPSO) are proposed to tune multivariable PID controller for the distillation column and compared the results with the RGA, MPSO and CMAES [22]. Amongst, PBPSO provided the best optimal value for all the three cases such as multivariable PID controller with decoupler, without decoupler and multivariable PI controller without decoupler. Recently proposed State transition Algorithm (STA) is applied to different benchmark problems which has the ability to reach a global optimal solution and shown that it has good convergence property when compared with a Real coded genetic algorithm (RCGA), Complementary Learning Particle Swarm optimization (CLPSO) and Strategy adaptation
Differential Evolution (SaDE) [23]. Herein, Implementation of State Transition Algorithm (STA) and STA-SBX Algorithm to tune multivariable PID controller for the distillation column is proposed and compared with already reported best results.

\section{Distillation Column Plant Model}

A binary distillation column plant with two inputs and two outputs is considered [24]. The pilot plant has eight trays with condenser and reboiler. A mixture of methanol and water is used as a feed in the system.

Controlled variables of the distillation column plant are composition of top and bottom products which are expressed in weight percentage of methanol ( $\%$ wt. $\mathrm{MeOH})$. Manipulated variables are reflux steam flow rate and reboiler steam flow rate which are expressed in $\mathrm{lb} / \mathrm{min}$. Linear dynamic transfer function model was developed by [24] which is given in equation 1 :

$$
\begin{aligned}
G_{p}(s) & =\left[\begin{array}{ll}
G_{p 11}(s) & G_{p 12}(s) \\
G_{p 21}(s) & G_{p 22}(s)
\end{array}\right] \\
& =\left[\begin{array}{ll}
\frac{12.8 e^{-s}}{16.7 s+1} & \frac{-18.9 e^{-3 s}}{21 s+1} \\
\frac{6.6 e^{-7 s}}{16.9 s+1} & -19.4 \frac{e^{-3 s}}{14.4 s+1}
\end{array}\right]
\end{aligned}
$$

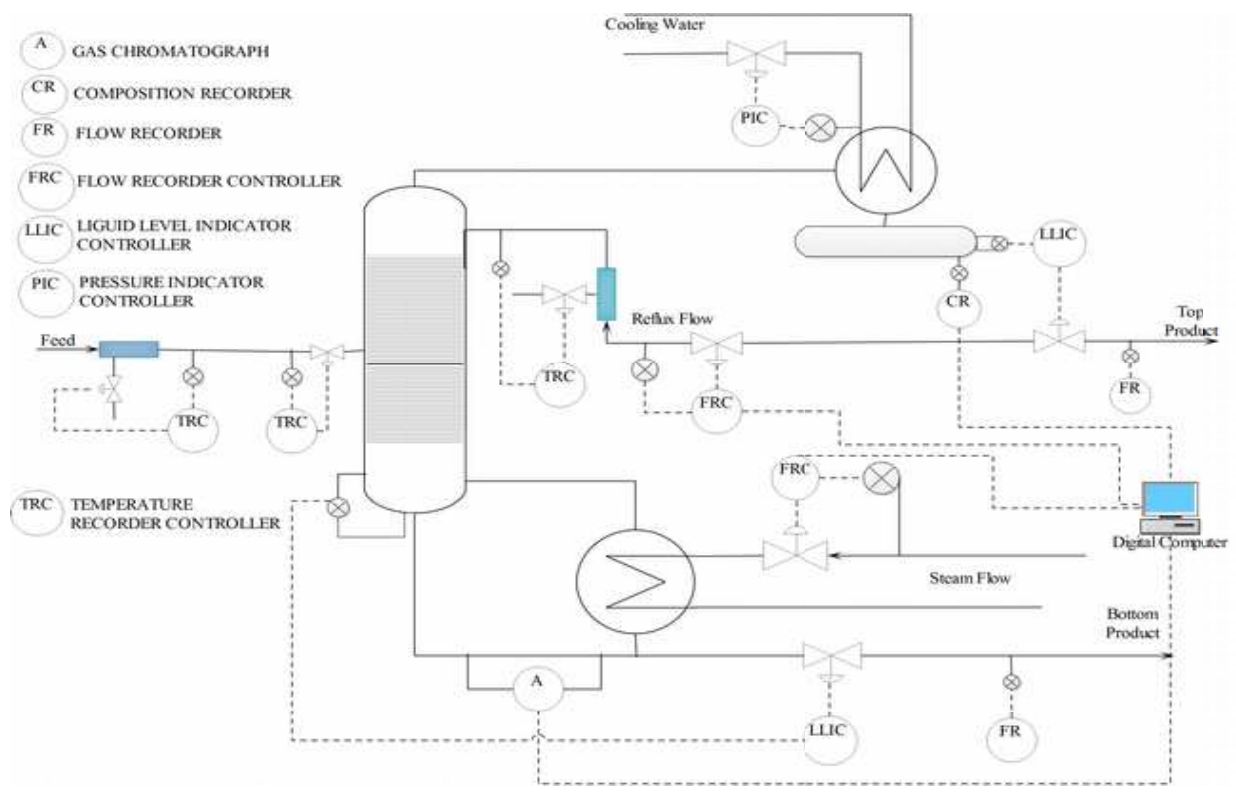

Figure 1. Schematic diagram of Distillation column Pilot plant [24] 
The steady-state decoupling matrix of the above plant model is given as [22].

$$
\begin{aligned}
D(s)=G_{p}^{-1}(s) & =\left[\begin{array}{ll}
D_{11}(s) & D_{12}(s) \\
D_{21}(s) & D_{22}(s)
\end{array}\right] \\
& =\left[\begin{array}{ll}
0.1570 & -0.1529 \\
0.0534 & -0.1036
\end{array}\right]
\end{aligned}
$$

\section{PID Controller}

Proportional Integral Derivative (PID) controller has been used in the process industry for several years. A block diagram of a simple closed-loop system consisting of a plant and a PID controller with unity feedback is shown in Figure 2. The purpose of the system is to keep the process output $(\mathrm{Y})$ close to the desired output $\left(\mathrm{Y}_{\mathrm{ds}}\right)$ in spite of disturbances. This is achieved by manipulating the process input (U) through the controller. The performance of the closed loop system is defined by the Integral performance measures and time response specifications.

The PID controller makes the plant less sensitive to changes in the surrounding environment and facilitates small changes in the plant. The transfer function of the PID controller is:

$G_{c}(s)=K_{p}+\frac{K_{i}}{s}+K_{d} s$

where $K_{p}$ is the proportional gain, $K_{i}$ is the integral gain and $K_{d}$ is the derivative gain. In the PID controller, the proportional part deals with the error of the system at present; the integral part takes the past into account and the derivative part estimates that will happen in the future. The proportional gain of the controller reduces error responses to disturbances. The integral of the error eliminates the steady state error and the derivative of the error dampens the dynamic response and thus improves the stability of the system. The controller has three parameters that can be adjusted like proportional gain $\left(K_{p}\right)$, Derivative gain $\left(K_{d}\right)$ and Integral gain $\left(K_{i}\right)$. The control loop performs well if the parameters are chosen properly. It performs poorly otherwise. Improper tuning may make the system become unstable. The procedure of finding the controller parameters is called tuning.

\subsection{PID controller for multivariable process}

The processes consist of each more than one input and one output is termed as multivariable process. Process transfer function model of $n X n$ is represented as

$$
G_{p}(s)=\left[\begin{array}{ccc}
G_{p 11}(s) & \cdots & G_{p 1 n}(s) \\
\vdots & \ddots & \vdots \\
G_{p n 1} & \cdots & G_{p n n}
\end{array}\right]
$$

Multivariable PID controller of $n X n$ is represented in coupled and decoupled form as given in equations 5 and 6 , respectively.

$$
\begin{aligned}
& K_{c}(s)=\left[\begin{array}{ccc}
K_{11}(s) & \cdots & K_{1 n}(s) \\
\vdots & \ddots & \vdots \\
K_{n 1} & \cdots & K_{n n}
\end{array}\right] \\
& K_{d c}(s)=\left[\begin{array}{ccc}
K_{11}(s) & \cdots & 0 \\
\vdots & \ddots & \vdots \\
0 & \cdots & K_{n n}
\end{array}\right]
\end{aligned}
$$

The PID parameters of are represented as

$$
\begin{aligned}
& {\left[\theta_{11}, \ldots, \theta_{n n}\right]} \\
& =\left[K_{p_{11}}, K_{i_{11}}, K_{d_{11}}, \ldots, K_{p_{n n}}, K_{i_{n n}}, K_{d_{n n}}\right]
\end{aligned}
$$

\section{State Transition Algorithm}

State transition algorithm (STA) is one of the heuristic random search algorithm based on the concept of state transition [23]. The algorithm of random search technique is given below [25].

- S1: Choose an $x$ as starting point and keep it as current solution;

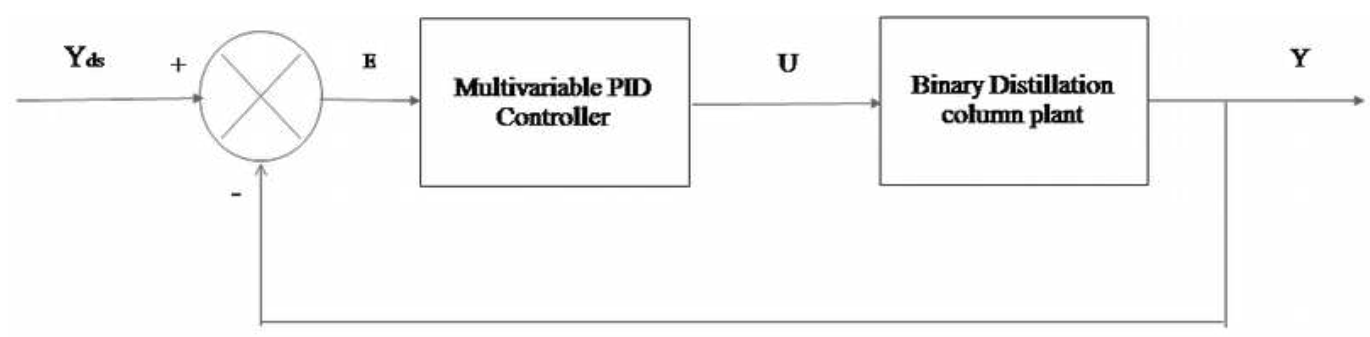

Figure 2. Block diagram representation of a closed-loop system 
- S2: Produce $d x$, random vector from the parameter space and add the current solution. Calculate the $f(x+d x)$ value;

- S3: If $f(x+d x)<f(x)$ keep the new solution as the current solution $(x=x+d x)$;

- S4: If the finishing criterion is reached, Stop, otherwise go to $S 2$.

STA has the formulation as a basic random search for the function $f(x)$ to be minimized as given in equation 8 :

$\left\{\begin{array}{l}x_{k+1}=A_{k} x_{k}+B_{k} u_{k} \\ y_{k+1}=f\left(x_{k+1}\right)\end{array}\right.$

where $x_{k+1}$ is calculated iteratively as given in equation 9:

$x_{k+1}=x_{k}+\alpha_{k} d_{k}$

where $x_{k}$ is the $k^{\text {th }}$ iteration point, $\alpha_{k}$ is the $k^{\text {th }}$ step, and $d_{k}$ is the $k^{\text {th }}$ direction. Transformation operators of STA are used to get the new state/solution which is found in [23] as follows.

Rotational transformation

$$
x_{k+1}=x_{k}+\alpha \frac{1}{n\left\|x_{k}\right\|_{2}} R_{r} x_{k}
$$

where $R_{r} \in \mathfrak{R}^{n X n}$ is the random matrix, $\alpha$ is the constant rotation factor with positive values. This transformation has the useful capability to look within the hyper sphere.

Translational transformation

$$
x_{k+1}=\chi_{k}+\beta R_{t} \frac{\chi_{k}-x_{k-1}}{\left\|x_{k}-\chi_{k-1}\right\|_{2}}
$$

It has the flexibility to search along the line with length of $\beta$ is a constant translation factor and $R_{t} \in \mathfrak{R}^{1}$ is a random variable with the range of $(0,1)$.

Expansion transformation

$$
x_{k+1}=x_{k}+\gamma R_{e} x_{k}
$$

It has the function of expanding component in the $x_{k}$ to search in the whole space.

Axesion transformation

$$
x_{k+1}=x_{k}+\delta R_{a} x_{k}
$$

It has functionality to look within the axes and enhances the single dimensional search. More detailed explanation of the expansion, rotation, axesion and translation transformations are given in [23].

Communication strategy is used to improve the premature convergence by incorporation of individual communication through crossover functions as shown in equation 14 and simulated binary crossover (SBX) is developed by Kalyanmoy Deb [26]. The algorithm which incorporated the crossover function in equation 14 and SBX crossover which is in equation 15 termed as STA and STA-SBX respectively.

$\left\{\begin{array}{l}Y_{1}=\delta_{c x} X_{1}+\left(1-\delta_{c x}\right) X_{1} \\ Y_{2}=\eta_{c x} X_{2}+\left(1-\eta_{c x}\right) X_{2}\end{array}\right.$

where $\delta_{c \mathrm{x}}$ and $\eta_{c \mathrm{x}}$ are independent cross over operators, which obeys distribution in the range $\left[\begin{array}{ll}0 & 1\end{array}\right]$.

$$
\left\{\begin{array}{l}
Y 1=0.5[(1-\beta) X 1+(1+\beta) X 2] \\
Y 2=0.5[(1+\beta) X 1+(1-\beta) X 2]
\end{array}\right.
$$

where $\beta$ is a random variable, obeying the following probability distribution

$$
\begin{cases}p(\beta)=0.5\left(\eta_{c}+1\right) \beta^{\eta_{c}} & 0 \leq \beta \leq 1 \\ p(\beta)=0.5\left(\eta_{c}+1\right) \frac{1}{\beta^{\eta_{c}+2}} & \beta>1\end{cases}
$$

where $p(\cdot)$ is the probability density function, $\eta_{c}$ is the distribution index [26].

Pseudo code for State Transition Algorithm is given below [23].

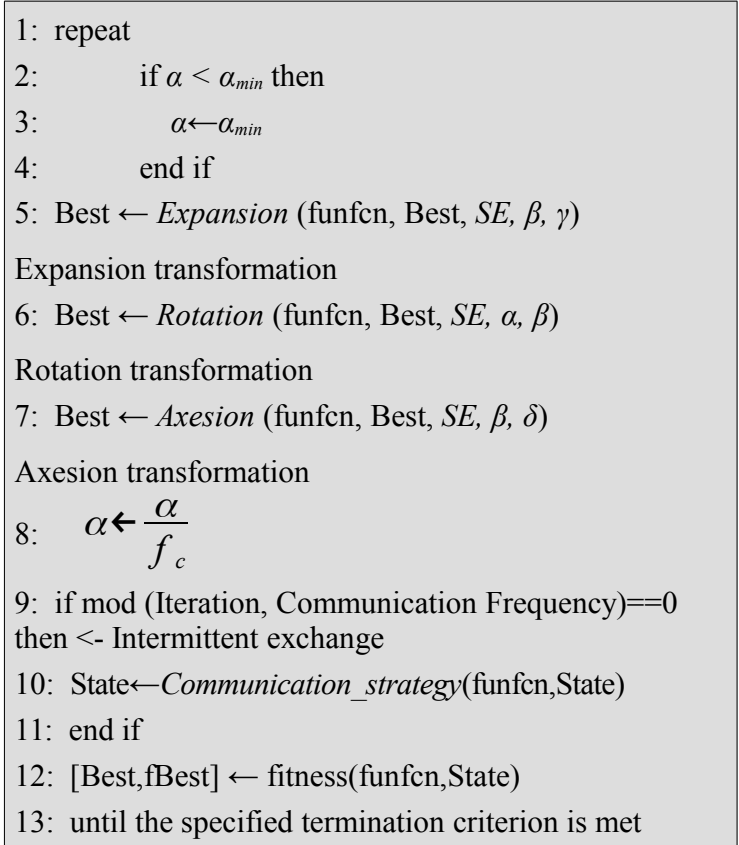




\section{Implementation of STA}

STA implementation of 2 by 2 Input / Output binary distillation column plant which has a transfer function model [24] is given in equation 1. The decentralized PID controller structure shown in equation 17 :

$$
K_{d c}(s)=\left[\begin{array}{cc}
k_{11}(s) & 0 \\
0 & k_{22}(s)
\end{array}\right]
$$

where $K_{d c}(s)$ decentralized PID controller transfer function. The tuning of PID controller is formulated as an optimization problem by minimizing the following Integral performance measures in equations $18 \& 19$.

$$
\begin{aligned}
& I A E=\int_{t=0}^{T}\left|e_{1}(t)\right| \cdot d t+\int_{t=0}^{T}\left|e_{2}(t)\right| \cdot d t \\
& I T A E=\int_{t=0}^{T} t .\left|e_{1}(t)\right| \cdot d t+\int_{t=0}^{T} t .\left|e_{2}(t)\right| \cdot d t
\end{aligned}
$$

where $e_{1}=\left[Y_{d s 1}-Y 1\right], e_{2}=\left[Y_{d s 2}-Y 2\right]$.

The parameters of $K_{d c}(s)$ is represented as

$$
\begin{aligned}
& {\left[\theta_{11}, \theta_{22}\right]} \\
& =\left[K_{p_{11}}, K_{i_{11}}, K_{d_{11}}, K_{p_{22}}, K_{i_{22}}, K_{d_{22}}\right]
\end{aligned}
$$

Tuning of the multivariable PID controller problem is formulated as an optimization problem considering IAE and ITAE as objective function by adjusting controller parameters through State Transition Algorithm.

\section{Case Studies and Simulation Results}

Simulations are carried out in three different cases for the tuning of multivariable decentralized PID controller such as PID controller with decoupler, without decoupler and PI controller without decoupler (Figures 3, 4 , and 5 respectively) by considering Wood and Berry distillation column model and are carried out for 20 independent trials using STA and STA-SBX algorithm for the maximum iteration count of 200 .

MATLAB-Simulink is run in Core 2 Duo processor, $2.2 \mathrm{GHz}$ and $2 \mathrm{~GB}$ RAM PC. Parameter settings of STA are kept unvarying for all the three cases those are given in Table 1.

Table 1. STA and STA-SBX tuning parameters

\begin{tabular}{|c|c|}
\hline $\boldsymbol{S E}, \boldsymbol{S N}$ & $\boldsymbol{N}$ \\
\hline$\alpha$ & 1 \\
\hline$\alpha_{\max }$ & 1 \\
\hline$\alpha_{\min }$ & $1 e^{-4}$ \\
\hline$\beta$ & 1 \\
\hline$\gamma$ & 1 \\
\hline$\delta$ & 1 \\
\hline$f_{c}$ & 2 \\
\hline$C F$ & 10 \\
\hline$\delta_{c x}$ & 0.6 \\
\hline$\eta_{c x}$ & 0.4 \\
\hline$\eta_{c}$ & 1 \\
\hline
\end{tabular}

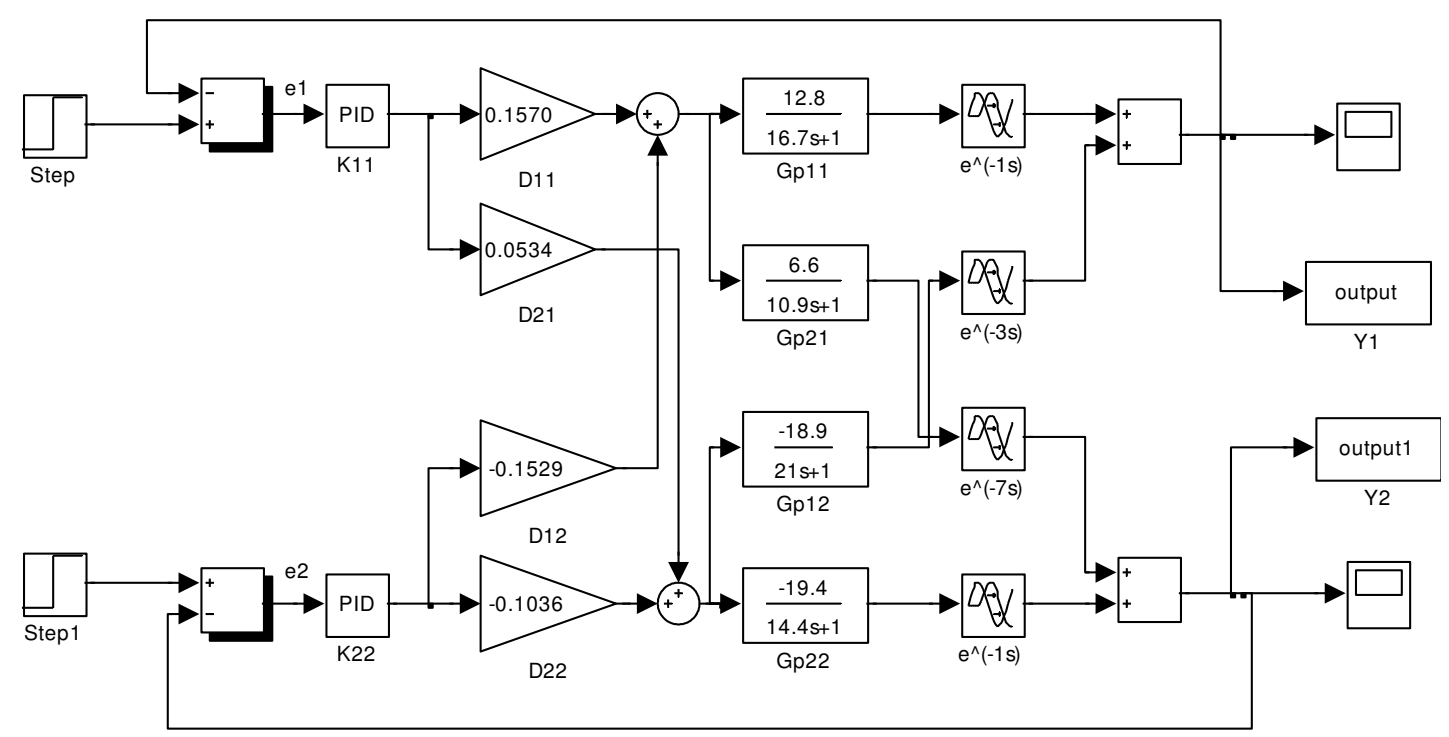

Figure 3. MATLAB-Simulink diagram for multivariable PID with decoupler 


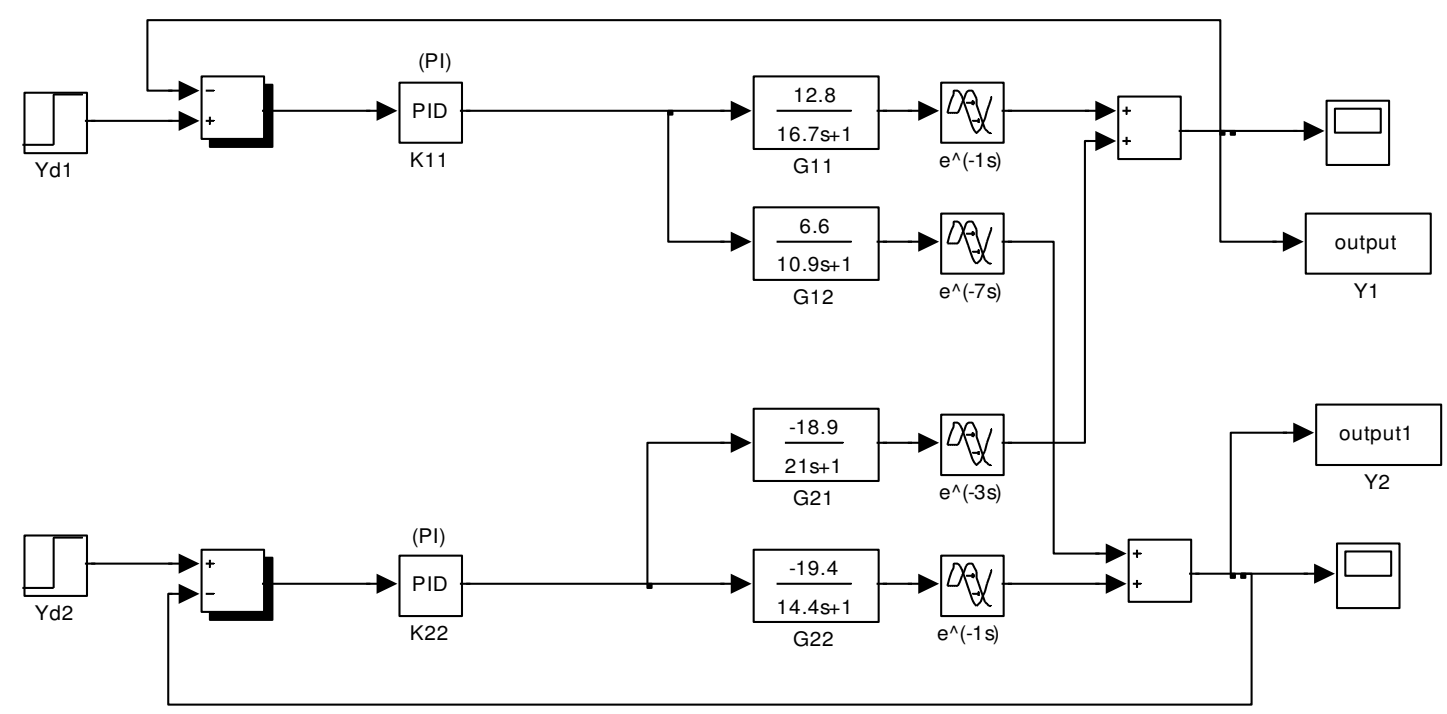

Figure 4. MATLAB-Simulink diagram for multivariable PID without decoupler

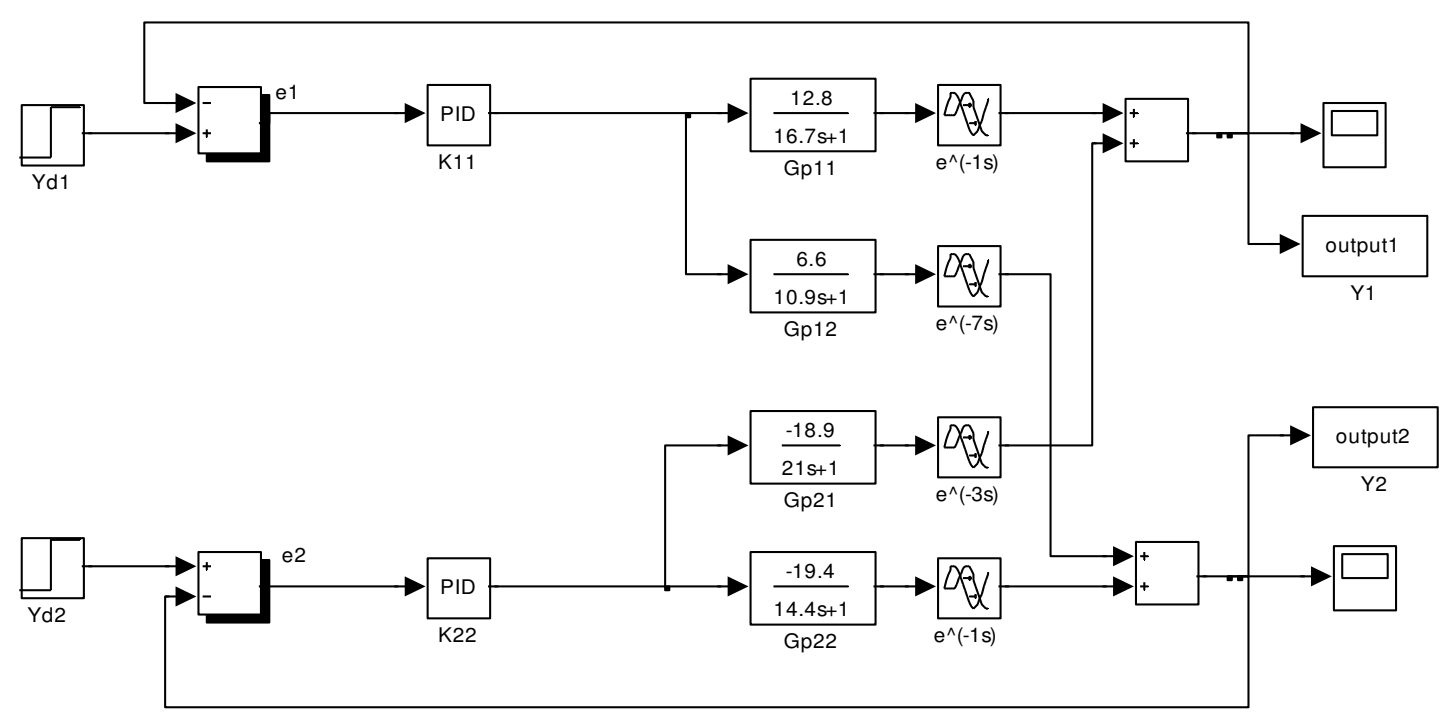

Figure 5. MATLAB-Simulink diagram for multivariable PI without decoupler.

where $N$ is the number of PID parameters, $C F$ is the communication frequency, $S E$ is search enforcements, $S N$ is the number of states and $f_{c}$ is the lessoning coefficient.

\subsection{Case study 1}

STA based tuning of multivariable decentralized PID controller for Wood and Berry system model with steady state decoupler, given in equations 2 and 3 , is considered for this study [22]. MATLABSimulink diagram for this study is shown in Figure 3. Considering the performance indices IAE and ITAE as objective functions, optimal results obtained out of 20 independents trails using STA and STA-SBX algorithms which are furnished in Table 2.

For IAE and ITAE, the step response curves of top product composition $\left(\mathrm{Y}_{1}\right)$ are shown in Figure 6 and Figure 7 respectively and step response curves for bottom product composition $\left(\mathrm{Y}_{2}\right)$ are shown in Figure 9 and Figure 10 respectively for the obtained optimal parameters. To compare the performance of the algorithm PBPSO algorithm based PID parameters is included in the Table 2 and also in the step response plot.

STA and STA-SBX algorithm is given better optimal result and transient response (Table 5) in both IAE and ITAE. 
Table 2. Optimal PID parameters obtained for Case Study 1

\begin{tabular}{|c|c|c|c|c|c|c|c|c|}
\hline \multirow{2}{*}{ Algorithm } & \multirow{2}{*}{$\begin{array}{c}\text { Performance } \\
\text { Index }\end{array}$} & $K_{p_{11}}$ & $K_{i_{11}}$ & $K_{d_{11}}$ & $K_{p_{22}}$ & $K_{i_{22}}$ & $K_{d_{22}}$ & $\begin{array}{c}\text { Fitness } \\
\text { Value }\end{array}$ \\
\cline { 3 - 9 } & IAE & 2.0000 & 0.1178 & -0.2493 & 1.9994 & 0.1250 & -0.2412 & 20.4109 \\
\hline STA & IAE & 2.0000 & 0.1256 & -2.0000 & 1.9964 & 0.1424 & -0.9737 & 16.6369 \\
\hline STA-SBX & IAE & 2.0000 & 0.1256 & -2.0000 & 1.9967 & 0.1424 & -0.9768 & 16.6369 \\
\hline PBPSO* & ITAE & 1.9978 & 0.1121 & -0.5443 & 1.9990 & 0.1485 & -0.5619 & 159.5911 \\
\hline STA & ITAE & 2.0000 & 0.1221 & -2.0000 & 1.9344 & 0.1488 & -0.8891 & 113.7329 \\
\hline STA-SBX & ITAE & 2.0000 & 0.1221 & -2.0000 & 1.9340 & 0.1487 & -0.8872 & 113.7329 \\
\hline
\end{tabular}

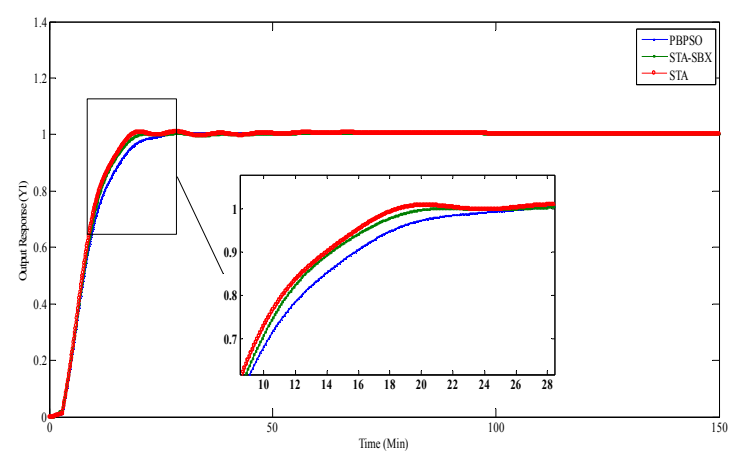

Figure 6. Output response of top product composition (Y1) for IAE

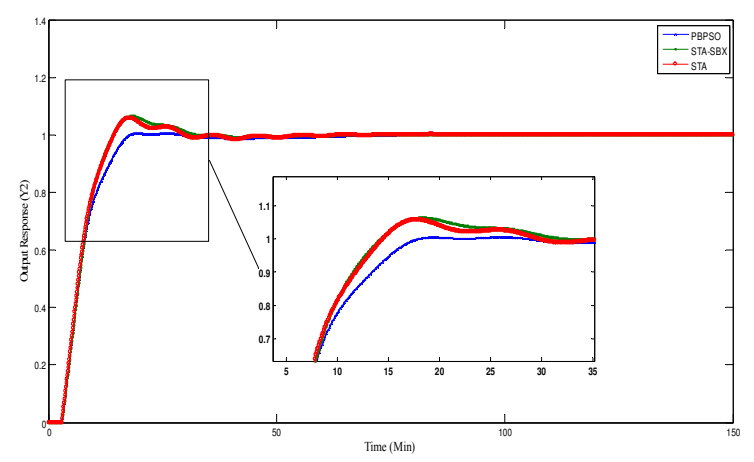

Figure 7. Output response of bottom product composition $\left(\mathrm{Y}_{2}\right)$ for IAE

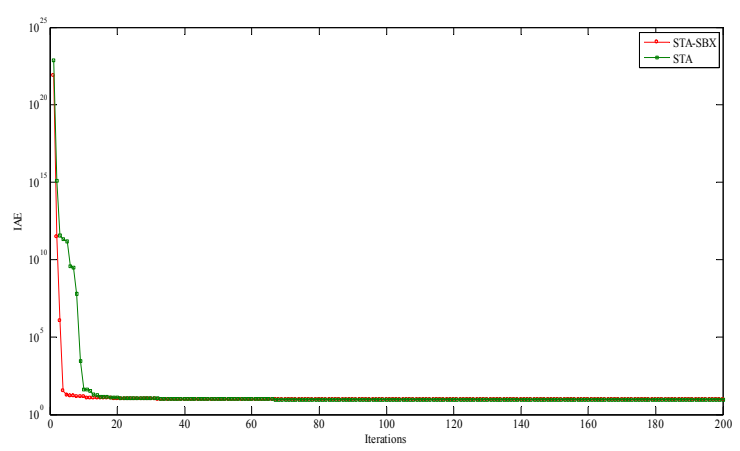

Figure 8. Convergence characteristics for IAE

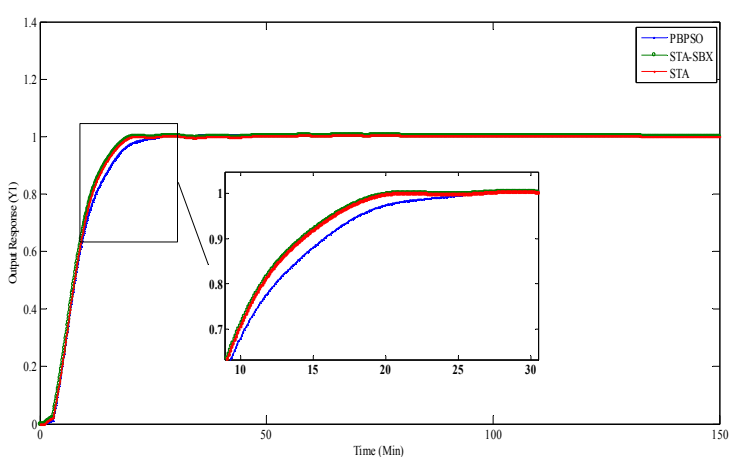

Figure 9. Output response for top product composition $\left(\mathrm{Y}_{1}\right)$ for ITAE

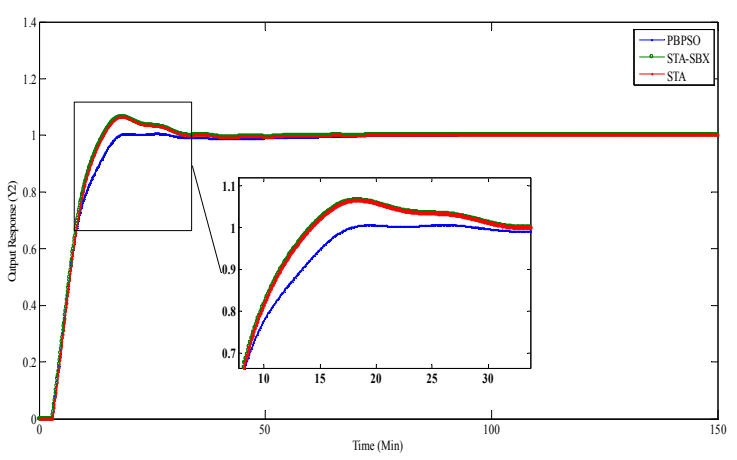

Figure 10. Output response of bottom product composition $\left(\mathrm{Y}_{2}\right)$ for ITAE

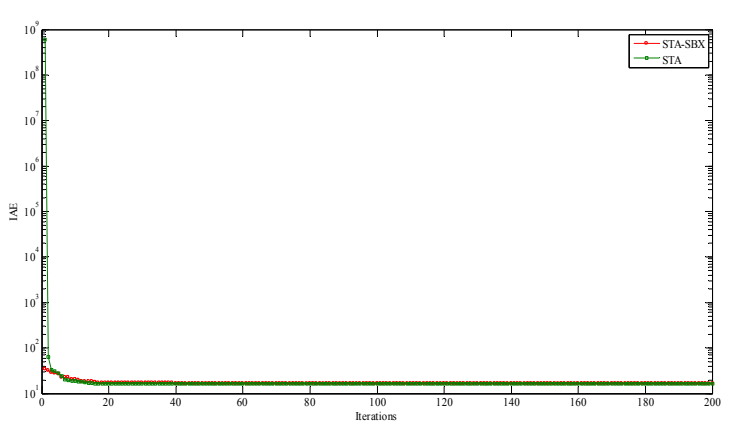

Figure 11. Convergence characteristics for ITAE 


\subsection{Case study 2}

STA based tuning of multivariable decentralized PID controller for Wood and Berry system model with steady state decoupler, given in equation 2, is considered for this study [22]. MATLABSimulink diagram is shown in Figure 4. Considering the performance index IAE as objective function, optimal results obtained out of 20 independents trails using STA and STA-SBX algorithms which are furnished in Table 3 . The step response curve of top product composition $\left(\mathrm{Y}_{1}\right)$ and bottom product composition $\left(\mathrm{Y}_{2}\right)$ are shown in Figures 12 and 13 for the obtained optimal PID parameters. To compare the performance of the algorithms PBPSO algorithm based PID parameters is included in the Table 3 and also in the step response plot. Convergence characteristic for IAE is shown in Figure 14.

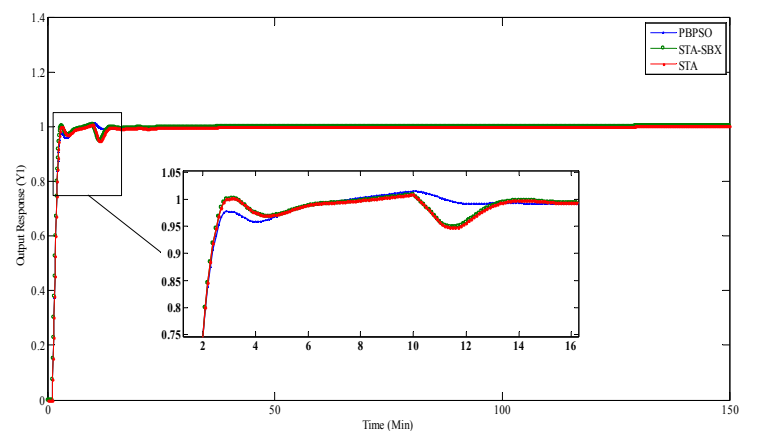

Figure 12. Output response of top product composition $\left(\mathrm{Y}_{1}\right)$ for IAE

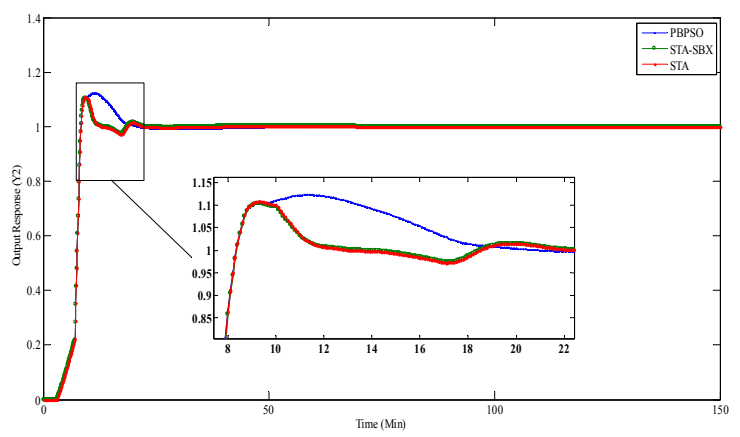

Figure 13. Output response of bottom product composition (Y2) for IAE

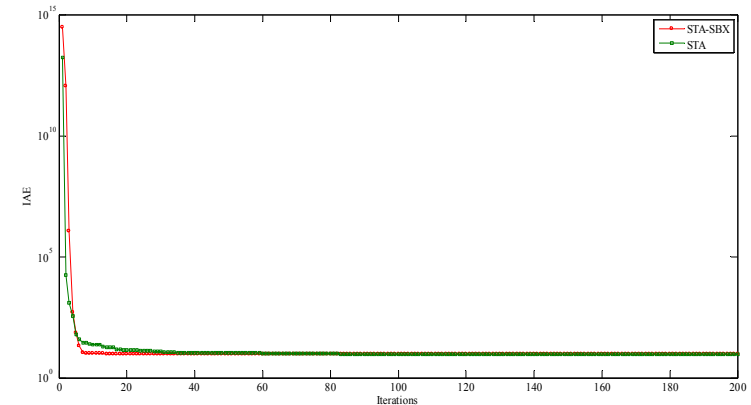

Figure 14. Convergence characteristics for IAE

STA and STA-SBX algorithm is given better optimal result and transient response (Table 5) for IAE.

\subsection{Case study 3}

STA based tuning of multivariable decentralized PI controller for Wood and Berry system model without steady state decoupler given in equation 2 is considered for this study [21,22].

MATLAB-Simulink diagram is shown in Figure 5. Considering the performance index IAE as the objective function, optimal result is obtained out of 20 independent trails using STA and STASBX algorithm which is furnished in Table 3 . The step response curve of top product composition $\left(\mathrm{Y}_{1}\right)$ and bottom product composition $\left(\mathrm{Y}_{2}\right)$ are shown in Figure 15 and Figure16 for the obtained optimal PID parameters. To compare the performance of the algorithms PBPSO algorithm based PID parameters is included in the Table 3 and also in the step response plot. Convergence characteristic for IAE is shown in Figure 17.

The time response specifications such as Rise time $\left(T_{s}\right)$, Settling time $\left(T_{r}\right)$ and Peak overshoot $\left(\mathrm{M}_{\mathrm{p}}\right)$ are calculated using MATLAB stepinfo command and are furnished in Table 5 or the optimal PID parameters obtained using STA and STA-SBX algorithms. For the comparison time response specification of PBPSO is included [22].

Table 3. Optimal PID parameters obtained in the Case Study 2.

\begin{tabular}{|c|c|c|c|c|c|c|c|c|}
\hline \multirow{2}{*}{ Algorithm } & \multirow{2}{*}{$\begin{array}{c}\text { Integral } \\
\text { Performance } \\
\text { Index }\end{array}$} & \multicolumn{6}{|c|}{ PID Controller parameters } & \multirow{2}{*}{$\begin{array}{c}\text { Fitness } \\
\text { Value }\end{array}$} \\
\hline & & $K_{p_{11}}$ & $K_{i_{11}}$ & $K_{d_{11}}$ & $K_{p_{22}}$ & $K_{i_{22}}$ & $K_{d_{22}}$ & \\
\hline PBPSO* & IAE & 0.9976 & 0.0025 & 0.3450 & -0.0313 & -0.0078 & -0.0155 & 13.1976 \\
\hline STA & IAE & 1.0000 & 0.0026 & 0.3055 & -0.0333 & -0.0073 & -0.0928 & 9.6692 \\
\hline STA SBX & IAE & 1.0000 & 0.0026 & 0.3049 & -0.0324 & -0.0073 & -0.0899 & 9.6699 \\
\hline
\end{tabular}

* PID parameters taken from [22] 
Table 4. Optimal PID parameters obtained in the Case Study 3

\begin{tabular}{|c|c|c|c|c|c|c|}
\hline \multirow{2}{*}{ Algorithm } & \multirow{2}{*}{$\begin{array}{c}\text { Integral } \\
\text { Performance } \\
\text { Index }\end{array}$} & $K_{p_{11}}$ & $K_{i_{22}}$ & $K_{p_{22}}$ & $K_{i_{22}}$ & \multirow{2}{*}{$\begin{array}{c}\text { Fitness } \\
\text { Value }\end{array}$} \\
\cline { 3 - 7 } & IAE & 0.8261 & 0.0027 & -0.0117 & -0.0068 & 13.3833 \\
\hline PBPSO* & IAE & 0.8957 & 0.0027 & -0.0133 & -0.007 & 10.3409 \\
\hline STA & IAE & 0.8955 & 0.0027 & -0.0133 & -0.007 & 10.3409 \\
\hline STA-SBX & & & & & & \\
\hline
\end{tabular}

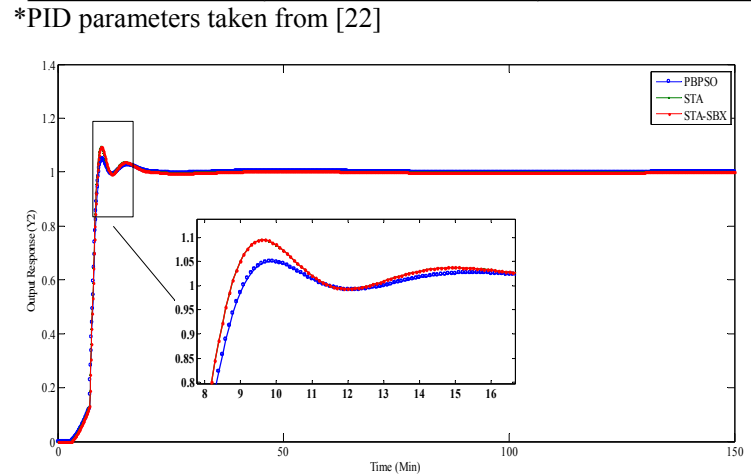

Figure 15. Output response of top product composition (Y1) for IAE

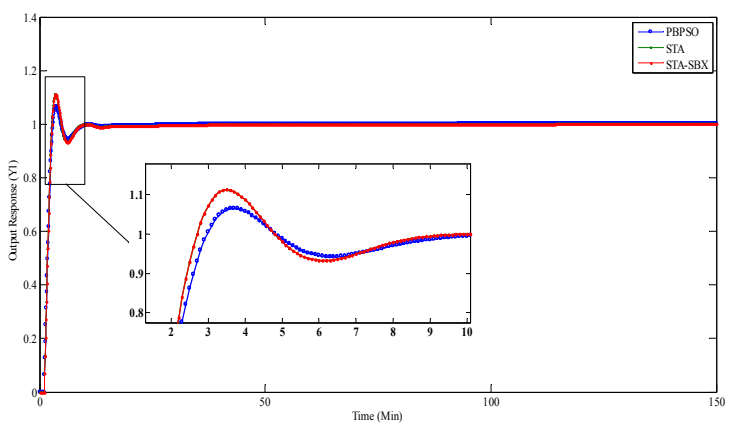

Figure 16. Output response of bottom product composition $\left(\mathrm{Y}_{2}\right)$ for IAE

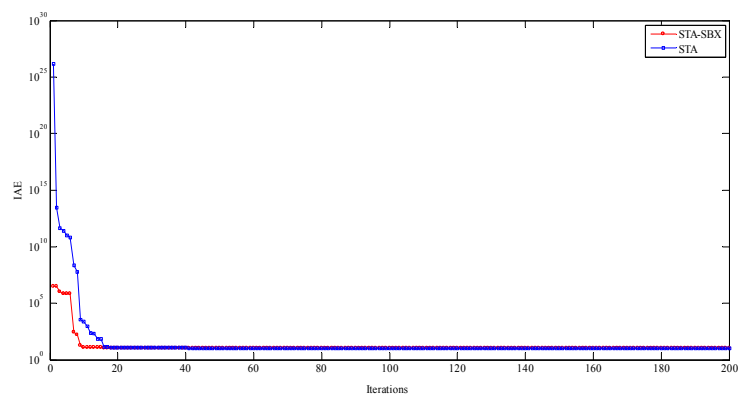

Figure 17. Convergence characteristics for IAE

Table 5. Comparison of time response specifications

\begin{tabular}{|c|c|c|c|c|c|c|c|c|}
\hline \multirow{2}{*}{$\begin{array}{l}\text { Case } \\
\text { Study }\end{array}$} & \multirow{2}{*}{ Algorithm } & \multirow{2}{*}{$\begin{array}{c}\text { Integral } \\
\text { Performance } \\
\text { Index }\end{array}$} & \multicolumn{3}{|c|}{ OUTPUT $Y_{1}$} & \multicolumn{3}{|c|}{ OUTPUT $Y_{2}$} \\
\hline & & & $M_{p}(\%)$ & $T_{r}($ Min $)$ & $T_{s}(\mathrm{Min})$ & $M_{p}(\%)$ & $T_{r}($ Min $)$ & $T_{s}(\mathrm{Min})$ \\
\hline \multirow{6}{*}{$\begin{array}{c}\text { Case } \\
\text { Study } 1\end{array}$} & PBPSO* & IAE & 0.58 & 11.82 & 18.16 & 0.55 & 9.65 & 15.10 \\
\hline & STA & IAE & 0.86 & 10.09 & 15.95 & 5.84 & 8.11 & 19.15 \\
\hline & STA-SBX & IAE & 0.86 & 10.08 & 15.95 & 5.79 & 8.12 & 19.15 \\
\hline & PBPSO* & ITAE & 0.58 & 11.82 & 18.16 & 0.55 & 9.65 & 15.10 \\
\hline & STA & ITAE & 0.43 & 10.43 & 16.41 & 6.48 & 7.72 & 20.96 \\
\hline & STA-SBX & ITAE & 0.43 & 10.43 & 16.41 & 6.46 & 7.73 & 20.94 \\
\hline \multirow{3}{*}{$\begin{array}{c}\text { Case } \\
\text { Study } 2\end{array}$} & PBPSO* & IAE & 1.44 & 1.25 & 2.59 & 12.35 & 3.05 & 16.15 \\
\hline & STA & IAE & 0.79 & 1.22 & 11.81 & 10.86 & 3.13 & 10.76 \\
\hline & STA-SBX & IAE & 0.75 & 1.22 & 11.72 & 10.43 & 3.09 & 10.72 \\
\hline \multirow{3}{*}{$\begin{array}{c}\text { Case } \\
\text { Study } 3\end{array}$} & PBPSO* & IAE & 6.52 & 1.45 & 7.06 & 5.02 & 2.16 & 9.92 \\
\hline & STA & IAE & 11.26 & 1.28 & 7.02 & 9.28 & 2.15 & 10.54 \\
\hline & STA-SBX & IAE & 11.24 & 1.29 & 7.02 & 9.60 & 2.15 & 10.54 \\
\hline
\end{tabular}

* PID parameters taken from [22] and calculated 

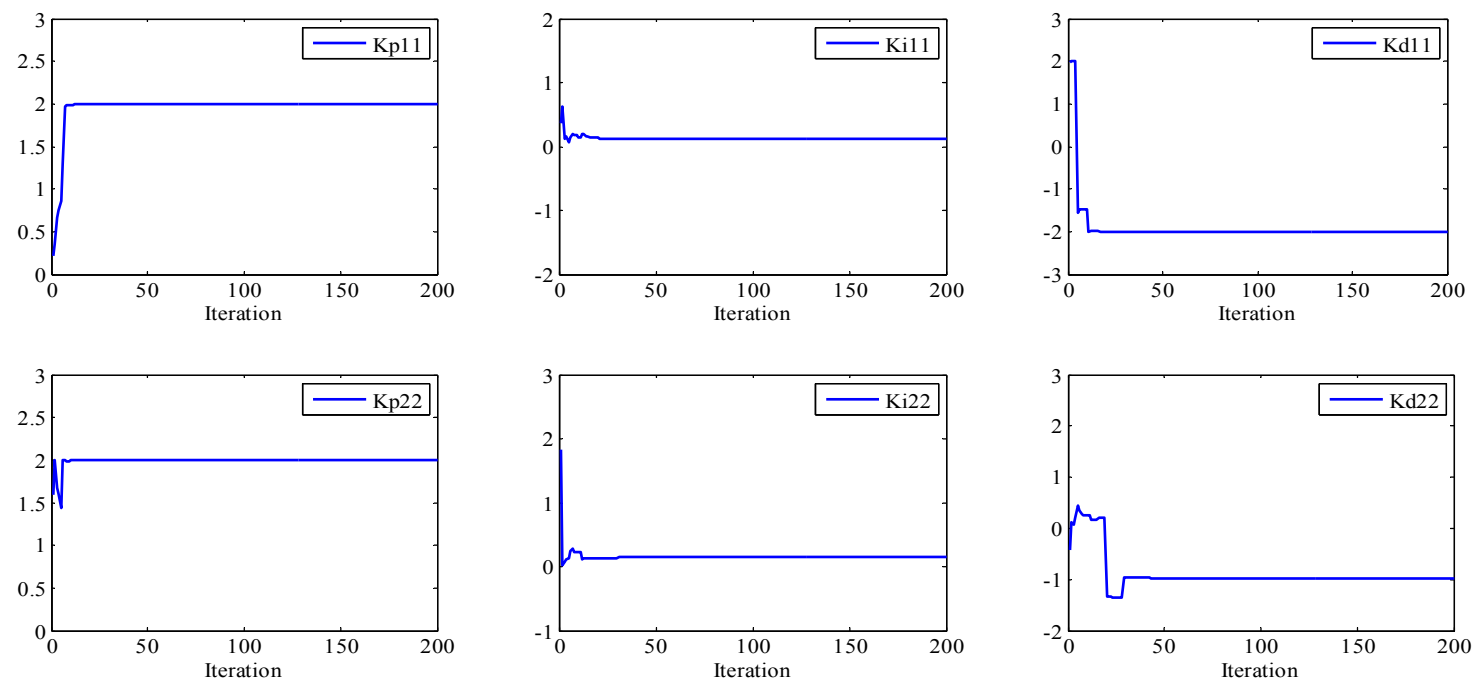

Figure 18. Convergence of optimal PID parameter with IAE for Case Study 1.

In the case study 1 , Rise time $\left(T_{r}\right)$ is improved while there are no appreciable change in the Peak Overshoot $\left(M_{p}\right)$ and Setting time $\left(T_{s}\right)$ in both the output $Y_{1}$ and $Y_{2}$. In the case study 3, Rise time is improved while there are no appreciable change in the Peak Overshoot $\left(\mathrm{M}_{\mathrm{p}}\right)$ and Setting time $\left(\mathrm{T}_{\mathrm{s}}\right)$ in both the output $\mathrm{Y}_{1}$ and $Y_{2}$. In Case Study 2, Rise time and Peak overshoot are improved and slight change in the settling time for the output $\mathrm{Y}_{1}$ and Settling time and Peak overshoot are improved and also slight change in Rise time for the output $\mathrm{Y}_{2}$.

\subsection{Statistical performance measures of STA}

Performance of STA and STA-SBX algorithms are assesed based on the statistical measures such as best (minimum of objective function), worst (maximum of objective function), standard deviation and average functional evaluation for twenty independent trials for all three cases is reported in Table.6. The performance of the STA-SBX algorithm is better than STA algorithm.

\section{Conclusion}

STA is implemented for the tuning of decentralized multivariable PI and PID controller with and without decoupler for two input and two output binary distillation column plant model. Simulation results from the various case studies imply that, STA and STA-SBX algorithms are provide the better optimal values over existing reported results in the literature.

Table 6. Statistical performance measures of STA and STA-SBX Algorithm

\begin{tabular}{|c|c|c|c|c|c|c|c|c|}
\hline \multicolumn{2}{|c|}{ Statistical Performance measures of STA and STA-SBX algorithm for three Case studies for 200 Iterations } \\
\hline $\begin{array}{c}\text { Case } \\
\text { Study }\end{array}$ & Algorithm & $\begin{array}{c}\text { Integral } \\
\text { Performance } \\
\text { Index }\end{array}$ & $\begin{array}{c}\text { Best } \\
\text { fitness }\end{array}$ & $\begin{array}{c}\text { Mean } \\
\text { fitness }\end{array}$ & $\begin{array}{c}\text { Standard } \\
\text { deviation } \\
\text { of fitness }\end{array}$ & $\begin{array}{c}\text { Worst } \\
\text { fitness }\end{array}$ & $\begin{array}{c}\text { Average } \\
\text { computation } \\
\text { time (Sec) }\end{array}$ & $\begin{array}{c}\text { Average } \\
\text { functional } \\
\text { evaluation }\end{array}$ \\
\hline \multirow{2}{*}{$\begin{array}{c}\text { Case } \\
\text { Study } 1\end{array}$} & STA-BTX & IAE & 16.6369 & 16.6369 & $5.39 \mathrm{E}-05$ & 16.6370 & 171 & 4300 \\
\cline { 2 - 10 } & STA & ITAE & 113.7329 & 124.2259 & 27.7056 & 221.2250 & 182 & 4539 \\
\cline { 2 - 10 } & STA-BTX & ITAE & 113.7329 & 113.7915 & 0.2402 & 114.8113 & 183 & 4584 \\
\hline $\begin{array}{c}\text { Case } \\
\text { Study } 2\end{array}$ & STA & IAE & 9.6692 & 9.9217 & 0.3723 & 11.0701 & 161 & 4481 \\
\cline { 2 - 10 } \\
\multirow{2}{*}{$\begin{array}{c}\text { Case } \\
\text { Study } 3\end{array}$} & STA-BTX & IAE & 9.6699 & 9.9048 & 0.3202 & 10.4414 & 176 & 4628 \\
\cline { 2 - 9 }$y$ & STA-BTX & IAE & 10.3409 & 10.9545 & 1.9242 & 17.6232 & 113 & 2877 \\
\hline
\end{tabular}


STA tuned parameters are given the improved response in the time response specifications particularly in rise time (Tr) for all three cases and slight improvements in Peak Overshoot (Mp) and Settling Time (Ts) in some cases. Two algorithms are reported by changing the crossover as STA and STA-SBX algorithm. Two algorithms are given the best fitness over already reported PBPSO. It is apparent from the statistical measures that the consistency of STASBX algorithm better than the STA algorithm.

\section{Acknowledgement}

This work was co-funded by European Union through European Regional Development Funds Structural Operational Program "Increasing of Economic Competitiveness" Priority axis 2, operation 2.1.2. Contract Number 621/2014.

\section{REFERENCES}

1. NICHOLS, N. B., J. G. ZIEGLER, Optimum Settings for Automatic Controllers, Trans. ASME, 64, 1942.

2. ASTROM, K., PID Controllers: Theory, Design and Tuning, 1995.

3. ANG, K., G. CHONG, Y. LI, PID Control System Analysis and Design, Control Systems, IEEE 26, 2006, pp. 32-41.

4. GE, H.-W., Y.-C. LIANG, M. MARCHESE, A Modified Particle Swarm Optimization-based Dynamic Recurrent Neural Network for Identifying and Controlling Nonlinear Systems, Computers \& Structures, vol. 85, 2007, pp. 1611-1622.

5. BACK, T., U. HAMMEL, H.-P. SCHWEFEL, Evolutionary Computation: Comments on the History and Current State, Evolutionary Computation, IEEE Transactions on, vol. 1, 1997, pp. 3-17.

6. DRACOPOULOS, D. C., Evolutionary Learning Algorithms for Neural adaptive Control, Springer-Verlag New York, Inc., 1997.

7. KROHLING, R., J. REY, Design of Optimal Disturbance Rejection PID Controllers using Genetic Algorithms, Evolutionary Computation, IEEE, vol. 5 2001, pp. 78-82.
8. JONES, A. H., B. PORTER, Genetic Tuning of Digital PID Controllers, Electronics Letters, vol. 28, 1992, pp. 843-844.

9. LEMAIRE, J., M. MORARI, B. OGUNNAIKE, W. RAY, Advanced Multivariable Control of a Pilot Plant Distillation Column, AIChE Journal, vol. 29, 1983, pp. 632-640.

10. ESCOBAR, M., J. O. TRIERWEILER, Multivariable PID Controller Design for Chemical Processes by Frequency Response Approximation, Chemical Eng. Science, vol. 88, 2013, pp. 1-15.

11. COElho, L. D. S., M. W. PESSÔA, A Tuning Strategy for Multivariable PI and PID Controllers using Differential Evolution Combined with Chaotic Zaslavskii Map, Expert Systems with App., vol. 38, 2011, pp. 13694-13701.

12. KIM, C., K. LEE, J. LEE, M. LEE, Analytical Design of Multiloop PID Controllers for Desired Closed-loop Responses, AIChE Journal, vol. 50, 2004, pp. 1631-1635.

13. DORMIDO, S., F. MORILLA, F. VÁZQUEZ, An Iterative Method for Tuning Decentralized PID Controllers, Proc. 14th IFAC World, 1999.

14. GANGULY, S., S. MAITI, N. D. SARAF, Some New Approaches for the Control of a Distillation Column and Their Experimental Evaluation on a Pilot Plant, Computers \& Chemical Engineering, vol. 19, 1995, pp. 399-404.

15. BERNERT, D. L. A., D. L. S. COELHO, L. DOS, PID Control Design for Chaotic Synchronization using a Tribes Optimization Approach, Chaos, Solitons \& Fractals, vol. 42, 2009, pp. 634-640.

16. DUAN, H., D. WANG, X. YU, Novel Approach to Nonlinear PID Parameter Optimization using Ant Colony Optimization Algorithm, J. of Bionic Engineering, vol. 3, 2006, pp. 73-78.

17. JAN, R.-M., R.-J. LIU, C.-S. TSENG, Robust PID Control Design for Permanent Magnet Synchronous Motor: A Genetic Approach, Electric Power Systems Research, vol. 78, 2008, pp. 1161-1168. 
18. KIM, T. T.-H., I. MARUTA, T. SUGIE, Robust PID Controller Tuning Based on the Constrained Particle Swarm Optimization, Automatica, vol. 44, 2008, pp. 1104-1110.

19. DU, H., S. WANG, J. ZHANG, J. ZHUANG, Self-organizing Genetic Algorithm based Tuning of PID Controllers, Information Sciences, vol. 179, 2009, pp. 1007-1018.

20. COELHO, L., V. MARIANI, Firefly Algorithm Approach based on Chaotic Tinkerbell Map Applied to Multivariable PID Controller Tuning, Computers \& Mathematics with Applications, vol. 64, 2012, pp. 2371-2382.

21. BASKAR, S., M. IRUTHAYARAJAN, Evolutionary Algorithms based Design of Multivariable PID Controller, Expert Systems with Applications, vol. 36, 2009, pp. 9159-9167.

22. FEI, M., M. I. MENHAS, H. PAN, L. WANG, Comparative Performance Analysis of Various Binary Coded PSO Algorithms in Multivariable PID Controller Design, Expert Systems with Applications, vol. 39, 2012, pp. 4390-4401.
23. GUI, W., C. YANG, X. ZHOU, State Transition Algorithm, Journal of Industrial and Management Optimization. vol. 8, 2012, pp. 1039-1056.

24. BERRY, M., R. WOOD, Terminal Composition Control of a Binary Distillation Column, Chemical Eng. Science, vol. 28, 1973, pp. 1707-1717.

25. HAMZAÇEBI, C., F. KUTAY, Continuous Functions Minimization by Dynamic Random Search Technique, Applied Mathematical Modelling, vol. 31, 2007, vol. 2189-2198.

26. DEB, K., A. KUMAR, Real-coded Genetic Algorithms with Simulated Binary Crossover: Studies on Multimodel and Multiobjective Problems, Complex Systems, vol. 9 1995, pp. 431-454. 